\title{
NITRIC OXIDE (NO)-CHEMOTHERAPY OF GLIOMAS: EXPERIMENTAL IN VITRO AND IN VIVO STUDIES OF MECHANISMS OF ANTITUMOR ACTIVITY OF LOW- MOLECULAR-WEIGHT DINITROSYL IRON COMPLEXES
}

\author{
N.A. Sanina \\ Russian Academy of Sciences, Institute of Problems of Chemical Physics, \\ 142432, Russian Federation, Chernogolovka, Acad. Semenov Av.,1. \\ DOI: 10.19163/MedChemRussia2021-2021-114 \\ E-mail: sanina@icp.ac.ru
}

An active search for new families of effective immunotropic drugs for treating of the brain tumors that act through certain cellular factors and have an inhibitory effect on tumor cells and/or stimulate the immune response is ongoing. In this regard, the search for NO donor compounds is of practical interest for the application in the clinic of a new modern strategy, viz. NO-chemotherapy of the brain tumors. Sulfurnitrosyl iron complexes containing the natural [ $\mathrm{Fe}(\mathrm{NO}) 2]$ fragments as NO donors have become increasingly important in recent years due to the discovery of their intriguing properties for biomedical applications [1]. The salt forms of dinitrosyl iron complexes (DNICs), as less toxic and more bioavailable complexes of this family, were obtained using thioderivative DNA bases [2] and aliphatic thioureas as sulfur-containing ligands [3]. For biological studies, a number of cells of different origin were used, including hepatocellular carcinoma HepG2, cervical carcinoma HeLa and breast adenocarcinoma MCF-7, brain tumor cell lines A-172, U87 MG and U251 MG, and non-cancerous Vero cells et al. Cytotoxicity of DNICs proved to be substantially different depending on the structure of the complexes and cell line. Analysis of NO donor activity of DNICs with thioderivative DNA bases showed that studied complexes reversibly release NO $\left(\approx 0.15 \cdot 10^{-3} \mathrm{M}\right)$, this amount being sufficient for exhibiting cytotoxic effect on human tumor cells of various histogenesis. Glioblastoma cells (A-172 line) were first shown to have extremely high sensitivity to NO generated by these complexes; rather low quantity of NO was shown to induce the arrest of the cell cycle and the cells death, which undoubtedly makes these compounds promising candidates for application in nitric oxide anti-glioma therapy. Studies of biological activity of DNICs with aliphatic thioureas have revealed that the cytotoxicity of complexes has no correlation with its NO-donating properties, and additional theirs intermediates decomposition and bioconversion have to be considered to contribute in their cytotoxic action.

The work has been supported by the Russian Foundation for Basic Research (the grant No. 20-03-00183 A).

\section{References}

[1] T.-T. Lu, Y.-M. Wang, C.-H. Hung, S.-J. Chiou, W.-F. Liaw, Inorg. Chem., 2018, 5720, 12425-12443.

[2] N.A. Sanina, G.I. Kozub, T.A. Kondratyeva, S.M. Aldoshin, Patent RF No. 2494104, 2013.

[3] N.A. Sanina, N.Yu. Shmatko, S.M. Aldoshin, Patent RF No. 2567245, 2015. 1Факультет наук о материалах, Московский государственный университет имени М.В.Ломоносова, 119234, Россия, Москва, ул. Колмогорова, 1, с.73. 